\title{
A EDUCAÇÃO POPULAR NOS MOVIMENTOS SOCIAIS DA SAÚDE: UMA ANÁLISE DE EXPERIÊNCIAS NAS DÉCADAS DE 1970 E 1980
}

POPULAR EDUCATION IN THE HEALTH SOCIAL MOVEMENTS: AN ANALYSIS

OF THE EXPERIENCES IN THE 70S AND 80S

Eduardo Navarro Stotz ${ }^{1}$

A Eymard Mourão Vasconcelos e ao pessoal da Aneps

\section{Introdução}

"Se eu fosse um antiquário, só teria olhos para as coisas velhas. Mas sou um historiador. É por isso que amo a vida". Esta frase de Henri Pirenne, contada por Marc Bloch (1993, p. 43) como uma anedota de viagem, serve de epígrafe da memória apresentada a seguir.

A história é "ciência dos homens no tempo", disse Bloch. Os historiadores são homens de seu próprio tempo, viventes mergulhados nas questões recorrentes e necessárias à inteligibilidade da sua época.

Comecemos então pela pergunta persistente quando se trata de educação na saúde: por que Educação 'Popular' e (em) Saúde? O termo 'popular', ao fazer distinções sociais e políticas, não separa ao invés de unir? Ou, formulada em outros termos, uma prática educativa na área da saúde não deveria ter caráter universal?

Podemos responder a esta pergunta reformulando-a. É possível uma educação universal numa sociedade dividida em classes, marcada pelo fenômeno da dominação?

Fato é que os profissionais de saúde — os médicos, sobretudo, mas não exclusivamente — têm enorme dificuldade de admitir que são condicionados pelos objetivos dos grupos ou classes dominantes numa certa época, e que esses objetivos não coincidem com a sua função precípua (Berlinguer, 1983). Ou seja, que a luta contra as doenças e a garantia do máximo nível de saúde sejam compatíveis com a exploração da força de trabalho e a incessante busca de lucros, principalmente devido às suas implicações para a vida social - individualismo, estresse, consumo desenfreado, violência.

De onde advém essa dificuldade? 
Aceitar as implicações de vivermos numa sociedade de classes, apesar do caráter público e democrático das instituições políticas, é um desafio à formação e à prática dos profissionais de saúde, estruturadas em saber técnico construído à margem da vida social e com pretensões de neutralidade política. Daí resulta também a resistência em admitir que as crenças nas quais se fundamenta seu saber possam ser relativizadas porque, como adverte Berlinguer (1983, p. 165), “as doenças tem historicidade própria e o nível de saúde está sujeito a avaliações controvertidas".

A Educação Popular pode enfrentar essa dificuldade, pois, além de reconhecer a existência da sociedade e da dominação de classes, assume a perspectiva das classes exploradas e dos grupos oprimidos. Por isso mesmo, a Educação Popular não se faz 'para' o povo, na medida em que não quer preestabelecer objetivos, conteúdos, palavras de ordem e verdades. Pelo contrário, se faz 'com' o povo: toma como ponto de partida do processo pedagógico o saber desenvolvido no trabalho, na vida social e na luta pela sobrevivência, e procura incorporar os modos de sentir, pensar e agir dos grupos e das camadas exploradas e oprimidas para ajudá-los em sua luta (Vasconcelos, 2005).

Decorre dessas premissas que a Educação Popular e (em) Saúde não é um campo técnico-científico, mas um 'movimento social' singular, composto de pesquisadores, profissionais e técnicos do chamado setor saúde, e de ativistas, técnicos e lideranças dos movimentos e organizações sociais comprometidos em participar e ampliar os esforços de emancipação das camadas trabalhadoras do povo brasileiro. Trata-se de um movimento que, em sua heterogeneidade, participa de visões de mundo diferentes (cristianismo, humanismo e socialismo), mas compartilha a abordagem freiriana da educação.

O objetivo da presente memória é analisar historicamente experiências do movimento social da saúde comprometidas com modos coletivos de aprendizado, de crítica da realidade e de aperfeiçoamento das lutas populares.

Tentar reconstruir os elos desse processo que tem, seguramente, mais de trinta anos e se espraiou por todo o país é, contudo, tarefa superior aos esforços de um único pesquisador. O problema é que uma sistematização dessa natureza requer, além do exame das experiências de Educação Popular e (em) Saúde acessíveis por meio de publicações ${ }^{2}$, a consideração de outras, na maior parte não escritas, vinculadas tanto a movimentos sociais que constituem formas "renovadas de fazer educação popular" (Souza, 2001, p. 31) quanto a movimentos e práticas de saúde "inovadoras" que não se identificam formalmente com esta tradição (Albuquerque, Pagliaro e Santos, 2004).

Nossa ambição aqui é mais limitada: pensamos dar conta de algumas experiências sobre educação nos movimentos da saúde, sistematizadas sob a forma de escritos publicados nas décadas de 1970 e 1980, principalmente no período compreendido entre 1975 e 1985, e, nesta medida, trazer uma contribuição para a história da Educação Popular e (em) Saúde. 


\section{A hegemonia da biomedicina e sua crise}

Para entender a emergência de movimentos de educação popular na saúde, temos de nos reportar à implantação, ao desenvolvimento e à crise do regime militar no Brasil entre 1964 e 1984, examinando tal processo sob o ângulo das políticas de saúde. Dentre as várias contribuições para esta análise selecionamos, pela identidade de propósitos com a Educação Popular, o pequeno e instigante ensaio sobre a medicina popular escrito por Maria Andréa Loyola (1984) para a primeira coletânea de textos do campo da Saúde Coletiva.

A autora chama atenção para o fato de que a ação estatal tem historicamente reforçado a 'medicina científica' (atualmente denominada biomedicina), “seguindo de perto o modelo internacional de saúde referido pela Organização Mundial de Saúde (OMS) que determina o primado da medicina científica produzida nos países desenvolvidos" (Loyola, 1984, p. 226-7).

Os pressupostos das políticas de saúde, continua Loyola, têm sido os mesmos da medicina científica na medida em que esta, ao deter o monopólio legítimo do saber médico na sociedade, é intolerante aos conhecimentos relativos à saúde produzidos fora de seu domínio. Isso implica, por outro lado, um processo de socialização de quadros profissionais (médicos, enfermeiros, administradores hospitalares) na ideologia de que o doente é um ser 'abstrato e indiferenciado', o que mascara as diferenças de classe atualizadas no tratamento diferencial dos doentes. É também uma ideologia que produz 'rendimentos simbólicos', ao desvincular, das prescrições médicas, os eventuais insucessos da terapêutica.

Vale citar aqui a conclusão da autora pelas implicações para a nossa reflexão, devido à importância da ideologia na saúde - uma área que prima pela afirmação da neutralidade da técnica:

\footnotetext{
"Imbuído de uma ideologia que tem por função mascarar as relações de classe que ela encobre, o médico atua no sentido de preservar o monopólio de seu saber e autoridade indiscutida que a sociedade lhe outorga para dispor da doença, até mesmo do corpo e das sensações de seu cliente. E sua atitude é tão mais autoritária quanto mais baixa é a classe social do doente que, pela distância sócio-lingüística e dos hábitos mentais que o separa do médico, encontra-se incapacitado de contra-argumentar com ele, isto é, de impor seu próprio discurso ao discurso 'forte' e definitivo do médico' (Loyola, 1984, p. 228).
}

Na leitura que Loyola faz da obra de Luc Boltanski, Les usages sociaux $d u$ corps, publicada em Paris em 1970, verifica-se que a medicina científica produz constantemente o distanciamento e a ruptura com o saber comum e o saber das outras medicinas que lhe fazem concorrência, disputando o monopólio legítimo do cuidado médico. 
A capacidade da medicina científica de manter esse monopólio parece estar bem assentada durante todo o período no qual se cria e expande a medicina previdenciária no Brasil, principalmente após a II Guerra Mundial. Mas, a partir de 1968, a atenção médica previdenciária vai mostrar-se insuficiente e de baixa eficácia (resolutividade) para lidar com os complexos problemas advindos de uma industrialização acelerada, em condições de intensa exploração, baixa incorporação dos trabalhadores ao mercado formal de trabalho e precária organização de infra-estrutura urbana. A crise da medicina científica vista sob o ângulo da perda de sua eficácia projeta a dimensão cultural enfatizada por Loyola. Tal preocupação é depois retomada no estudo de Madel Therezinha Luz (1996) sobre a história social da homeopatia: ao longo da secular dissociação entre ciência e arte na medicina ocidental, o médico torna-se um especialista que, ao abrir mão das categorias de cura e saúde, raciocina e age de modo incompreensível ao doente e a sua família.

\section{O reformismo autoritário (1970-1977)}

A consciência dos limites da medicina oficial se dá no contexto mais amplo do reformismo autoritário implementado pelo governo do general Geisel, expressão das implicações políticas da continuidade do projeto de desenvolvimento capitalista a partir do Estado. A tecnocracia governamental percebe, em meados da década de 1970, que impulsionar este tipo de desenvolvimento implica diminuir as tensões sociais acarretadas pelas políticas de arrocho salarial e de concentração de renda até então vigentes. Não se trata de uma percepção abstrata: problemas agudos de sobrevivência da população trabalhadora, decorrentes da intensa e elevada acumulação de capital às expensas do trabalho e da desproteção social, acarretam uma verdadeira 'crise sanitária', com "aumento da mortalidade infantil, dos índices de desnutrição, eclosão de epidemias como a meningite, ressurgimento ou aumento da incidência de certas doenças endêmicas como a tuberculose" (Luz, 1986, p. 148). A epidemia de meningite torna o quadro dramático por ocorrer no centro de gravidade da economia do país, São Paulo.

A canalização política do descontentamento social aparece nas vitórias do Movimento Democrático Brasileiro, partido oficial de oposição, nas eleições proporcionais (Congresso Nacional e assembléias legislativas).

Os tecnocratas do regime militar reconhecem, no II Plano Nacional de Desenvolvimento, que o desenvolvimento social precisa acontecer de modo paralelo e progressivo ao desenvolvimento econômico, com aumento da renda nacional, diminuição da pobreza absoluta e extensão da previdência social. O paradoxo de um regime militar que procura legitimar-se socialmente 
é equacionado com agudeza e audácia por Régis de Castro Andrade (1982) num pequeno texto sobre a política social.

Vejamos alguns dos traços mais relevantes do processo de "normalização institucional das relações sociais capitalistas" (Andrade, 1982, p. 96) encaminhado pelo Estado nesse período em suas manifestações na área da saúde.

Como Sarah Escorel (1995) observa pertinentemente, o governo do general Geisel começa com a criação do Ministério da Previdência e Assistência Social (MPAS), e o final de sua gestão conclui-se com a organização da medicina previdenciária por meio do Instituto Nacional de Assistência Médica da Previdência Social (Inamps), operando por meio de convênios com o setor privado. A cobertura populacional da medicina previdenciária amplia-se com a inclusão de segmentos de assalariados na cidade (empregadas domésticas) e no campo (trabalhadores rurais). Contudo, estão fora deste esquema de proteção baseada na contribuição previdenciária os segmentos de trabalhadores urbanos e rurais do setor 'informal'.

Oliveira e Teixeira (1986) observam a existência, no âmbito do Estado brasileiro, de uma histórica divisão entre uma saúde pública coletiva e preventiva e uma medicina previdenciária, individual e curativa. A criação do MPAS e a instituição da medicina previdenciária levam, pela primeira vez na história republicana, à criação de um Sistema Nacional de Saúde (SNS). De acordo com os autores:

“O SNS (Lei n. 6229, de 17 de julho de 1975) é constituído do complexo de serviços, do setor público e do setor privado, voltados para ações de interesse da saúde (...) organizados e disciplinados nos termos desta lei, abrangendo as atividades que visem a promoção, prevenção e recuperação da saúde" (Oliveira e Teixeira, 1986, p. 253).

O Ministério da Saúde (MS) passa a ganhar importância. E isso se dá por meio da criação de novas agências institucionais, implementação de políticas e reativação das conferências nacionais de saúde. Dentre as instituições e programas que, no âmbito estatal, tentam viabilizar a política de saúde nos moldes propugnados pela Lei do SNS, destacam-se a Financiadora Especial de Projetos (Finep), o Centro Nacional de Recursos Humanos do Instituto de Pesquisas Econômicas (Ipea) e o Programa de Preparação Estratégica de Pessoal de Saúde (PPREPS/MS).

De acordo com Escorel (1995), a Reforma Sanitária é bem-sucedida somente porque conta com uma rede de sustentação no próprio Estado autoritário, então iniciando um processo de 'distensão' social. Assim, enquanto a Finep viabiliza o desenvolvimento - e a ampliação de quadros — de pesquisas estratégicas no Instituto de Medicina Social da Universidade do Estado do Rio de Janeiro (IMS/Uerj) e na Escola Nacional de Saúde Pública 
Sérgio Arouca da Fundação Oswaldo Cruz (Ensp/Fiocruz)33, o PPREPS propicia a formação dos profissionais de saúde por meio de convênios com as secretarias estaduais de saúde e de apoio aos projetos docente-assistenciais desenvolvidos pelos departamentos de Medicina Preventiva. Tudo estava vinculado à lógica dos programas de extensão de cobertura sob nova modalidade assistencial (Teixeira, 1982). O esforço resulta na instituição do campo da saúde coletiva e definição de residências vinculadas à saúde pública (multiprofissionais) ou à medicina (social, preventiva, comunitária).

É assim que, apoiado nesta rede institucional, o movimento sanitário estruturado em torno da 'academia' (os departamentos de medicina preventiva da USP e Unicamp, a Ensp, o IMS/Uerj), do movimento estudantil (médicos residentes), do Centro Brasileiro de Estudos em Saúde (Cebes) e da Associação Brasileira de Saúde Coletiva (Abrasco) — começa a tomar forma e se expande, em pleno regime militar ${ }^{4}$.

\section{A Medicina Comunitária e a emergência da Educação Popular na saúde}

Retomemos o fio da meada. Falamos na importância das conferências nacionais de saúde na estratégia do Ministério da Saúde para implementar o SNS. Vejamos agora o que recomenda a V Conferência Nacional de Saúde, realizada em agosto de 1975. Segundo Pellegrini, Ramos e Ribeiro (1984, p. 208), “a Conferência indica: a ampliação da cobertura através da extensão da rede de serviços; a integração e regionalização de serviços; o apoio ao desenvolvimento de formas simplificadas de atendimento; e a participação da população nos serviços que lhes são oferecidos".

Percebe-se com clareza, nestas recomendações, a incorporação das proposições da Medicina Comunitária. Cecília Donnangelo escreve então Medicina e estrutura social: o campo de emergência da medicina comunitária, tese de livre-docência defendida na Faculdade de Medicina da USP em agosto de 1976. Em Saúde e sociedade, Donnangelo e Pereira (1979) retomam esta perspectiva, mostrando que, desde a sua origem nos Estados Unidos, esta modalidade de assistência médica dirigia-se a grupos populacionais definidos pela pobreza e carência de direitos.

A participação comunitária 5 é estimulada como a forma dos grupos mais pobres aproveitarem os próprios recursos para superar a sua 'marginalidade' e integrarem-se ao processo de desenvolvimento econômico. Programas de melhoria da habitação, de saneamento, de educação de base, de animação social e de associativismo procuram materializar essa pretensão em favor da integração social dos pobres (Pellegrini, Ramos e Ribeiro, 1984). A retórica da superação da pobreza mal consegue esconder que se trata de afastar o espectro da Revolução Cubana a rondar o continente americano desde meados da década de 1960. 
A Medicina Comunitária apresenta-se como um aspecto particular desses programas de ação: procura estender a assistência médica sob uma forma simplificada, expressa "no uso de pessoal médico com diferentes níveis de treinamento", cujo símbolo mais conhecido é o "médico de pé descalço na China" (Donnangelo e Pereira, 1979), e na identificação entre comunidade e sociedade no nível do espaço geográfico. Esta delimitação, aliás, vai permitir a criação de instrumentos adequados:

\footnotetext{
“Registrar a comunidade, diagnosticá-la, identificar a sua configuração restrita, definir o seu padrão de saúde, avaliar os seus recursos constituem instrumentos de trabalho que devem permitir o estabelecimento de um continuum entre o diagnóstico e a interferência em nível individual e o diagnóstico e a interferência em nível coletivo" (Donnangelo e Pereira, 1979, p. 92).
}

Sem dúvida, o aspecto mais importante da medicina comunitária é a sua possibilidade de criar ou reorientar interesses e objetivos de uma 'comunidade', propiciando, assim, a constituição de sujeitos e atores, tensionando os limites da estrutura social e de poder vigentes. É nesta possibilidade que as esquerdas, católica (comunidades eclesiais de base) e comunista (Partido Comunista Brasileiro, Ação Popular, Partido Comunista do Brasil), vão apostar.

\section{A Educação Popular nos movimentos populares da saúde}

Uma sistematização de experiências educativas sob a perspectiva de uma renovação da medicina comunitária é elaborada por Antonio Ivo de Carvalho (1976), ao refletir sobre a 'intervenção social' na saúde em contexto de periferia urbana. Trata-se de um documento importante para entender a tomada de posição teórico-metodológica das esquerdas no aproveitamento das circunstâncias geradas pelo reformismo autoritário do governo Geisel.

Ao identificar uma 'diluição conceitual' dos significados da medicina comunitária à proporção que esta se difunde, o autor ressalta a importância de esclarecer os sentidos possíveis que a intervenção social assume na saúde, se 'instrumento (meio)' ou 'finalidade' do processo educativo:

\footnotetext{
“No primeiro caso, a educação é o objetivo central, enquanto os problemas de saúde constituem o terreno a partir do qual esse objetivo se concretiza. No segundo caso, o objetivo se prende à obtenção de melhorias no nível de saúde da comunidade e a prática educativa é uma forma de viabilizar esse objetivo, ou seja, de conferir maior eficácia ao combate à doença. Considerando-se, por um lado, que esse combate à doença pode ter um significado bastante amplo (a elevação do nível de consciência
} 
é uma forma de combater a doença já que pode implicar, por exemplo, no desencadeamento de pressões por melhores condições de vida) e, por outro, que os processos educativos, a partir de questões de saúde, efetivamente implicam em ações de saúde (e isso significa combater a doença), pode-se sugerir que a diferença entre os dois tipos de proposta é uma sutileza sem importância" (Carvalho, 1976, p. 20-21).

A escolha de uma ou outra forma de intervenção traz implícita a problemática da manutenção ou da mudança social, ainda que isso não implique a adoção de uma perspectiva revolucionária.

Estrella Bohadana (1982), planejadora urbana, adota o delineamento proposto por Carvalho em sua análise dos trabalhos de saúde que visam à participação da comunidade. Para a autora, destacam-se duas vertentes: na primeira, caracterizada por ter como objetivo central a mobilização e organização da comunidade, encontram-se projetos autônomos 6 e propostas apoiadas pela Igreja Católica, a exemplo da diocese de Goiás Velho (Goiás), Nova Holanda (Rio de Janeiro), Nova Iguaçu (Rio de Janeiro), Acapuna (Paraná), Aratuba (Ceará) e Perpétuo Socorro (Amapá). Na segunda vertente, privilegia-se a extensão da assistência médica. Nesta, encontram-se projetos de natureza acadêmica, financiados com fontes externas, a exemplo dos projetos desenvolvidos pela Universidade de Londrina, pela Unicamp e pela Uerj, e projetos financiados pelo Estado, com ajuda externa (Usaid), com destaque para o Projeto Montes Claros, da Secretaria de Estado de Saúde de Minas Gerais (Stralen, Souza e Vieira, apud Bohadana, 1982).

A divisão é esquemática: serve apenas para identificar a linha principal do trabalho educativo na saúde, uma vez que, no desenvolvimento da prática, as linhas podem coexistir com diferentes ênfases ou os impasses de uma linha podem acabar por propiciar a adoção de outra, como se verifica, aliás, numa das experiências que serão analisadas a seguir7.

\section{A experiência de Porto Nacional}

Em 1968, um grupo de profissionais de saúde da USP, oriundos da Juventude Universitária Católica (JUC), dirige-se a Goiás para conversar com Dom Tomás Balduíno a respeito de sua idéia de desenvolver um trabalho de Medicina Comunitária na Amazônia. Ao parar em Porto Nacional para abastecimento, localizaram o prédio vazio de uma 'unidade mista'. Assim começa a experiência do trabalho comunitário de saúde de Porto Nacional, no norte de Goiás - hoje Tocantins. Mas eles, a rigor, não começam a história e logo vão descobrir referências anteriores de atuação progressista e de esquerda na área médica, reprimidas pelo regime militar8. 
No relato de Oliveira,

"A equipe inicial, constituída por cinco médicos, duas assistentes sociais, uma enfermeira e uma educadora atuando na Unidade Mista da Osego [Organização de Saúde do Estado de Goiás/Secretaria de Estado de Saúde] — Unidade Sanitária acoplada a Hospital de 50 leitos, — percebe a dificuldade de ações comunitárias tendo por base o atendimento médico à doença e se dispõe a sair para as ruas" (Oliveira, 1983, p. 24-25).

A proposta de valorização das parteiras, a criação de postos rurais, a valorização do artesanato são algumas das iniciativas encaminhadas a partir da criação da Comunidade de Saúde, Desenvolvimento e Educação (Comsaúde) que favorece a participação da população no planejamento, na execução e na avaliação das atividades. É interessante constatar a inclusão destas atividades no espírito da Medicina Comunitária, tal como analisada por Donnangelo e Pereira (1979) e referida por Pellegrini, Ramos e Ribeiro (1984):

“O trabalho com os desnutridos foi o início do trabalho efetivo com a família, nos aspectos de Nutrição, Higiene, Moradia, União, Participação. É ainda nesta fase que se estabeleceu um programa de valorização do artesanato e foi possível, após um ano de melhoria de habitação, a criação do $1^{\circ}$ Centro Comunitário" (Oliveira, 1983, p. 25).

A equipe da Comsaúde, atuando no hospital estadual, por intermédio da prefeitura, celebra convênio com a Faculdade de Medicina de Goiás para criar estágio rural em 1972. Cinco anos depois, inicia-se o Projeto Goiás, projeto docente-assistencial apoiado pela Fundação Kellog e pela Organização Pan-Americana de Saúde (Opas) com intermediação do Ministério da Saúde. A par dos avanços institucionais que levam ao reconhecimento do projeto como modelo de serviço para países de Terceiro Mundo (Opas, 1979), exercendo influência na região, a Comsaúde transforma-se em Conselho Comunitário de Saúde, que se organiza com base nos movimentos das lavadeiras e trabalhadoras domésticas, dos lavradores e da Associação dos Artesãos e Artífices de Porto Nacional (Oliveira, 1983, 2004).

Então, entre 1981 e 1983, já no quadro da abertura política, o programa institucional se desarticula. A perseguição política à equipe e, por fim, a implantação do Programa de Interiorização de Ações de Saúde e Saneamento (PIASS), paradoxalmente para fazer o que o Projeto Goiás já fazia, marca o fim de uma fase. A base popular organizada na Comsaúde mantém em funcionamento as atividades, inclusive o atendimento médico nesse período, nos Centros Comunitários (Oliveira, 1983). Daí em diante começa uma fase em que a prefeitura assume os postos de saúde, com a equipe da Comsaúde retomando o funcionamento do hospital. No final da década de 1980, com o hospital público 
não mais cumprindo o papel de suporte ao trabalho comunitário, a equipe de profissionais e movimentos populares criam o Hospital Padre Luso, entidade filantrópica, conveniado ao Sistema Único de Saúde (SUS) (Oliveira, 2004).

\section{Meio Grito}

Na experiência que leva este nome, a equipe das Comunidades Eclesiais de Base (CEBs) e os agentes da diocese de Goiás, sob a inspiração de D. Tomás Balduíno, desenvolve - com a assessoria de Carlos Rodrigues Brandão, Neide Esterci e José Ricardo Ramalho, do Centro Ecumênico de Documentação e Informação (Cedi) do Rio de Janeiro - uma pesquisa sobre as condições de vida e os direitos do povo à saúde nas periferias das cidades da diocese. A pesquisa nasce das 'comissões de saúde' organizadas por lavradores (pequenos proprietários, meeiros, diaristas), lavadeiras, donas de casa, professoras rurais, estudantes (Equipe das Comunidades, 1988).

Por que a pesquisa recebe o nome de Meio Grito? Porque quem descobre o significado do direito à saúde adquire a força para se unir e gritar por esse direito, mas são pessoas que apenas participam da pesquisa; por isso gritam 'meio grito', não o grito 'inteirado' do povo (Equipe das Comunidades, 1988). A pesquisa dá origem a uma Coordenação de Saúde que vai entrar em contato com diferentes experiências na diocese. A pesquisa informa e mobiliza e a coordenação articula e mantém a direção. Em seguida, começam a ser organizados Encontros Populares de Saúde nos vários municípios: “nestas ocasiões, questões referentes à saúde do povo são levantadas em seus determinantes econômico-sociais e analisadas em suas implicações políticas" (Equipe das Comunidades, 1988, p. 134).

A percepção da situação de exploração e de marginalidade leva a pensar em atitudes concretas de reivindicação. Contudo, em vez de uma mobilização imediata, a coordenação admite a necessidade do povo 'conhecer bem' seus direitos. As trocas de experiências e discussões por meio dos encontros continua. Num desses encontros, cria-se a Comissão Regional de Saúde, que vai provocar, meses depois de sua criação, um encontro popular de maiores proporções. Nasce então a idéia de uma cartilha, a ser escrita com a participação do povo, com a sua linguagem. A cartilha é uma 'lamparina para alumiar a picada': deve trazer o conhecimento sobre o que ainda não se sabe, principalmente quanto ao direito à saúde.

A necessidade de discutir para aprofundar certos temas e reforçar as reivindicações populares é transformada em exigência metodológica: as questões levantadas em grupos num Encontro Popular devem compor um 'roteiro de discussão' sobre o problema 'saúde' com grupos de pessoas de diferentes comunidades. 
A aplicação do questionário na Abordagem de Grupos resulta num impressionante processo de discussão envolvendo 69 grupos com uma composição variável de cinco a 52 pessoas, abrangendo um total de 831 participantes (lavradores, mulheres da roça e da periferia, prostitutas, lavadeiras, pequenos comerciantes, diaristas, empreiteiros e subempregados, grupos de evangelho, comunidades protestantes). Tudo se passa durante um ano, de outubro de 1978 a outubro de 1979.

A pesquisa propicia a inteiração do grito, mas ainda não é o grito. Daí a necessidade da organização para lutar pelos direitos sociais à saúde, uma luta que vai além da "doença e não é apenas uma luta contra os maus serviços de cura da doença" (Equipe das Comunidades, 1988, p. 193).

\section{A experiência de Cabuçu}

Dois médicos, apoiados pela Diocese de Nova Iguaçu, iniciam em 1974, no bairro de Cabuçu, o trabalho de 'ação de saúde'. Cabuçu é um bairro onde vive uma população de cinco mil habitantes, espalhados em barracos de alvenaria, sem qualquer infra-estrutura urbana. É neste bairro periférico de Nova Iguaçu, então com 617.329 habitantes, que se desenvolve a ação de saúde organizada como prestação de serviço médico.

A experiência traz à tona a problemática de uma população de periferia urbana pobre, com quadros de desnutrição e tuberculose e com um "componente psicossomático absurdo", e demanda um consumo de medicamentos e de assistência médica enorme na opinião do médico, Antonio Ivo de Carvalho (Bohadana, 1982, p. 112-13). Nesse contexto, é promovido um Curso de Saúde, com o objetivo de treinar uma equipe de moradores para desempenhar atividades simplificadas de saúde, ao tempo em que se propicia a reflexão sobre essa prática, de modo a desenvolver um processo comunitário no bairro.

Em meados de 1975, o ambulatório financiado pela Inter American Foundation já dispõe de quatro médicos e alguns equipamentos. As atividades pedagógicas incluem vários círculos de gestantes que também conversam sobre os problemas mais gerais de saúde e as condições de vida dos moradores do bairro. Mas a avaliação ao final deste ano impõe uma revisão do caminho. Não se quer estimular a participação nas atividades do ambulatório e, sim, criar um espaço onde "as pessoas, a partir do debate e reflexão sobre seus problemas de saúde, pudessem eleger e se engajar em formas concretas de enfrentamento coletivo desses problemas" (Carvalho, apud Bohadana, 1982, p. 114).

A redefinição de rumo implica emprestar à ação de saúde o objetivo de mobilizar e organizar a comunidade a partir dela própria. O método escolhi- 
do é um curso de dinâmica de saúde que procura: 1) debater livremente os diversos problemas de saúde, momento em que se faz a vinculação de experiências individuais e familiares de doenças com as condições coletivas de carência do bairro; 2) identificar as causas desses problemas; 3) levantar as experiências associativas da comunidade; 4) planejar ações coletivas prioritárias para o enfrentamento dos problemas.

No decorrer desses cursos, organizados em seis bairros de Nova Iguaçu, experiências associativas se constituem e se entretecem nos Encontros de Saúde realizados a cada dois meses. A necessidade de coordenação e melhoria do sistema de representação leva, em outubro de 1978, à realização de uma assembléia geral de todos os grupos envolvidos. Organizam-se comissões de bairros que vão, logo depois, dar suporte ao Movimento de Amigos de Bairro de Nova Iguaçu (MAB).

A organização do MAB propicia o encaminhamento de reivindicações por saneamento básico, educação, transporte, infra-estrutura urbana e saúde. O conjunto das reivindicações é elaborado no I Ciclo de Debates Populares do MAB: planejamento integrado de recursos destinados à saúde, com prioridade para os serviços básicos, organização de uma rede de postos articulada aos prontos socorros e a um hospital geral, um infantil e uma maternidade. Reivindica-se o funcionamento do Hospital da Posse, adquirido pelo Inamps e até o momento fechado. Além da retomada do diálogo entre poder público e população numa plataforma de democratização política, propõe-se a primeira forma do chamado 'controle social', assim expresso: "Que o Movimento Amigos de Bairro de Nova Iguaçu tenha participação no planejamento da aplicação dos recursos destinados à saúde no município" (Bohadana, 1982, p. 117).

\section{Movimento de Saúde da Zona Leste}

O movimento de saúde que se torna conhecido por suas raízes em bairros pobres da Zona Leste da capital paulista tem início no Jardim Nordeste, situado na região sanitária de Itaquera-São Mateus (Comissão do Movimento, 1984; Fantin, 1988). Por meio de uma atividade ligada à Igreja Católica, os moradores encaminham um abaixo-assinado reivindicando um serviço de saúde aos órgãos competentes. Surge então a idéia de organizar uma farmácia popular que conta com o apoio de estudantes de medicina, muitos dos quais oriundos do movimento estudantil (Fantin, 1988).

Maristela Fantin, em seu estudo de mestrado, preocupa-se em saber qual a natureza das relações entre esses estudantes e as donas de casa que constituem a base do movimento da saúde no bairro de Jardim Nordeste. A autora destaca a contribuição dos estudantes ao apontar para as causas das 
doenças e favorecer a percepção sobre a necessidade de uma atuação mais ampla do que a atividade assistencialista (coleta e doação de alimentos, e mesmo a farmácia popular). Os estudantes, por sua vez, aprendem com as donas de casa a realizar um trabalho popular e a fazer saúde de uma forma diferente daquela aprendida na universidade. As diferenças e as contradições devido à posição social, ao grau de escolaridade, à idade e aos objetivos são enfrentadas, discutidas e amadurecidas no próprio processo de organização e mobilização ${ }^{9}$.

É nesse contexto que surge a idéia de reivindicar a instalação de um posto de saúde. A formação de um grupo comum denominado de Comissão de Saúde encaminha em 1976 a luta por essa conquista. Portanto, nesse ano, quando os primeiros médicos-sanitaristas da rede pública da Secretaria Estadual de Saúde de São Paulo chegam a Jardim Nordeste, o movimento já está em curso10.

No decorrer das atividades exigidas para a conquista do posto de saúde - reuniões nas casas dos moradores, coletas de abaixo-assinados, caravanas à Secretaria de Estado de Saúde (SES), elaboração de um jornal —, os membros das comissões se educam ao mesmo tempo em que modificam a realidade. Assim é que, em 1978, conquistam o Centro de Saúde.

Mas, como diz Fernando Pessoa, todo começo é imprevisível. A precariedade dos serviços prestados pelo Centro de Saúde à população, manifestada pelas constantes reclamações contra o atendimento, leva a Comissão de Saúde a pensar numa forma de participar do funcionamento do centro. Os profissionais de saúde e estudantes descobrem uma norma técnica da SES que se materializa na experiência de um conselho no município de Mauá, formado, porém, pela elite local (vereadores, médicos, diretores de escola, delegados de polícia, Rotary). A Comissão de Saúde aproveita a oportunidade institucional, mas propõe um novo tipo de conselho, um conselho representativo da população, que acabou por ser aceito pela SES:

“O primeiro conselho de saúde da Zona Leste foi constituído no bairro do Jardim Nordeste, sendo formado por doze mulheres eleitas pelo voto direto. Esse conselho foi eleito com aproximadamente oito mil votos, em um bairro onde na época havia vinte mil habitantes. Isto significava uma grande vitória que se deu em março de 1979" (Fantin, 1988, p. 57).

Médico que não cumpre horário, pediatra que não examina pacientes, coordenador do centro que não aceita a autoridade do conselho - estes são problemas que mobilizam a atenção do Conselho de Jardim Nordeste. Esta última questão provoca um atrito com a SES, resultando na ocupação do Centro de Saúde pelo conselho por oito dias (Fantin, 2003).

Nos anos seguintes, acontece a ampliação da experiência, com a eleição de 16 conselhos próximos à região de São Mateus. As eleições diretas tor- 
nam-se um método 'universal', com a inclusão do voto dos analfabetos e a divulgação de fotos e 'currículos' dos candidatos nos bairros e na imprensa. Em 1983, ocorre o Encontro das Comissões e Conselhos de Saúde da Zona Leste, unificando o movimento. As reivindicações aprovadas no encontro de 18 e 19 de março, do qual participam aproximadamente 150 pessoas de 37 bairros, tratam, a curto prazo, da ampliação e melhoria dos Centros de Saúde, da construção de hospitais públicos e prontos-socorros e ambulatório do Inamps, e da oficialização do Regimento dos Conselhos; a médio prazo, do saneamento básico e da organização de um conselho na Regional da Saúde; a longo prazo, do "fim dos convênios com a Medicina do Lucro", de um "atendimento à saúde que seja público, de boa qualidade e igual para todos" e da "participação da população na fiscalização e controle do funcionamento de todos os Serviços de Saúde" (Comissão do Movimento, 1984, p. 12-13). Em agosto do mesmo ano, realiza-se a caravana que conduz três mil pessoas de 80 bairros para apresentar estas reivindicações aos secretários de saúde do Estado, do Município e ao representante do Inamps.

A ampliação e a institucionalização do movimento sob a forma de conselhos e sua unificação deixa, porém, o bairro 'desassistido'. Os novos conselhos organizados em 1985 já não se dão a partir de um trabalho de base. Por outro lado, o papel dos técnicos na articulação, direção e formação dos conselheiros ganha maior peso. O poder de decisão, que antes era partilhado por todos, passa a se concentrar nas mãos dos que têm mais conhecimento e competência (Fantin, 1988).

\section{O movimento popular e a saúde em questão}

É importante lembrar que as experiências aqui relatadas e suas conquistas Porto Nacional, Goiás Velho, Nova Iguaçu e Zona Leste de São Paulo — acontecem numa conjuntura de intensificação da luta popular, em especial dos operários metalúrgicos. As conquistas se dão, portanto, numa fase de ascensão das lutas populares que vão questionar a própria existência do regime militar.

É em 1979, na cidade de Lins (SP), sob o patrocínio da arquidiocese da cidade, que acontece o I Encontro Nacional de Experiências em Medicina Comunitária (Enemec) ${ }^{11}$. A atuação dos profissionais de saúde nesse encontro é majoritária (Costa, 2004).

A preparação do II Enemec já é caracterizada por uma forte articulação entre os grupos populares na saúde. O encontro realiza-se em 1980, em Recife (Oliveira, 1983). O dinamismo da organização mantida pelo trabalho comunitário de Porto Nacional, pelas CEBs em Ceres e Goiás Velho (experiência do Meio Grito), de base freiriana, e pelos sindicatos de trabalhadores em Itapuranga favorece a escolha de Goiânia para sede do III Enemec (Oliveira, 2004). 
A evolução do processo entre 1979 e 1981 vai da troca de experiências à reflexão sobre a necessidade de lutar por mudanças no modelo de assistência à saúde. Daí resulta a proposta de transformar o Enemec em Movimento Popular de Saúde (Mops). Esta é uma das resoluções do III Encontro, realizado em Goiânia em maio de 1981. Escolhe-se uma Coordenação Nacional do Mops para levantar as bandeiras de luta pelo controle dos serviços de saúde pelos trabalhadores, pela unificação do serviço previdenciário urbano, pela saúde preventiva e é criado o Dia Nacional de Luta pela Saúde, coincidindo com o Dia Mundial da Saúde (Oliveira, 1983; 2004).

Contudo, as divergências sobre a 'institucionalização' do trabalho de medicina comunitária tomam conta dos debates. O Mops já nasce 'rachado'. O pano de fundo das divergências é de cunho político geral: a radicalização das divergências fundamenta-se em 'estratégias' que opõem os militantes dos partidos (Partido dos Trabalhadores, Partido Comunista Brasileiro, Partido Comunista do Brasil) que participam do movimento. A maioria a favor do caminho da 'institucionalização' está organizada por delegados de Goiás, Sul do Pará, Mato Grosso, Zona Leste de São Paulo e Rio de Janeiro (Oliveira, 2004).

O símbolo da institucionalização é a definição do Dia Nacional de Luta pela Saúde, a ser comemorado no dia 7 de abril de cada ano (Oliveira, 1983). O caminho da institucionalização vai prevalecer inclusive do ponto de vista da luta democrática, como se constata na ampla aceitação pelas esquerdas, em 1984, da eleição indireta para a presidência da República, realizada por meio de um colégio eleitoral predominantemente de direita. É a 'transição pactuada' entre militares e civis, estes últimos representados por Tancredo Neves e José Sarney, porta-vozes dos dois partidos (Movimento Democrático Brasileiro - MDB e Aliança Renovadora Nacional - Arena) que haviam sustentado, na oposição e na situação, o regime militar, mas agora unidos na Aliança Democrática.

O capítulo político das lutas populares é, sem dúvida, mais grandioso, ainda que atravessado pelas divergências e disputas políticas e ideológicas. O trabalho de mobilização e organização popular, estruturado por uma aliança entre os profissionais e técnicos da saúde e as lideranças e os ativistas populares, faz avançar a luta pelo direito à saúde, afirmada em tentativas de organizar os serviços de modo alternativo que questionam o modelo vigente de atenção à saúde. São contribuições fundamentais ao processo da Reforma Sanitária, que se inicia na VIII Conferência Nacional de Saúde e culmina na Constituinte.

Tudo indica que o Movimento de Saúde da Zona Leste representa o ponto mais avançado das lutas populares pela saúde dessa época. Um movimento que propõe o local de moradia como base de um processo de organização, mobilização e conscientização popular na conquista da saúde, entendida de modo amplo. 
Mas desde então o processo político se desloca dos movimentos populares para o âmbito das instituições do Estado:

“Um olhar retrospectivo (Escorel, 1998) aponta para as limitações de uma escolha estratégica. A autora afirma que os articuladores do movimento sanitarista priorizaram a ocupação dos 'espaços públicos', separando-se do movimento popular de origem. Passaram, em decorrência, a sofrer as limitações das alianças impostas pelas instituições públicas de saúde, ora transformadas em locus de contra-hegemonia. Na verdade, o argumento a favor da contra-hegemonia somente teria plausibilidade, na perspectiva gramsciana de 'guerra de posições', se amparada numa ampla e forte aliança entre profissionais e técnicos do setor público e os potenciais beneficiários desse setor, os trabalhadores da cidade e do campo. Isso não aconteceu" (Stotz, 2003, p. 30).

Pode-se alegar que as experiências da participação popular são projetadas na figura institucional do conselho de saúde, um dos mecanismos de controle social do SUS. A instituição dos conselhos municipais e estaduais de saúde a partir de 1991, compondo uma extensa estrutura, legitima a municipalização da saúde com a transferência de recursos do governo federal e a ênfase na gestão pactuada entre as autoridades de saúde nos três níveis de governo. Mas os conselhos passam a sofrer as conseqüências de seu atrelamento à estrutura das secretarias - onde prevalece, sob um sistema comandado a partir do governo federal, a lógica da gestão e não a do planejamento. Exigências de capacitação dos conselheiros (especialmente do segmento dos usuários) para entender os meandros de um processo de negociação sempre à margem dos conselhos tomam o lugar da indispensável reorientação dos objetivos, dos métodos e da dinâmica das conferências de saúde.

Em boa medida, a fragilidade dos conselhos de saúde é expressão da falta de dinamismo de suas bases sociais numa conjuntura caracterizada pela ofensiva neoliberal que tem início na gestão de Fernando Collor de Melo (19901992) e que continua nas duas gestões de Fernando Henrique Cardoso (entre 1994 e 2002) na presidência da República. A desmobilização social está associada ao desemprego estrutural, ao empobrecimento das classes trabalhadoras e ao clima político favorável à competição e ao individualismo. Um novo tipo de assistencialismo é implementado pelo Estado para aqueles incapazes de se manter no mercado de trabalho. Esta é a conjuntura em que ainda vivemos, apesar das esperanças populares de que o governo Lula possa revertê-la.

As articulações que surgem nesta conjuntura são o resultado das dificuldades criadas pelo desfecho do processo da Reforma Sanitária anteriormente comentado e das próprias limitações da mobilização social. De um lado, o I Congresso Nacional do Mops realizado em Goiânia entre 13 e 17 de julho de 1994 consegue reunir as tendências que estão separadas desde 
1981 (Mops, 1994). Mas não há acordo possível com a linha proposta de um movimento 'de massa', organizado pela base para lutar por um outro sistema de governo. A divisão acaba por inviabilizar a implementação da política proposta, pois é aprovada com uma diferença de apenas seis votos (Leite, 2004). Alguns dos profissionais de saúde e professores universitários comprometidos com a educação popular que não aceitam a proposta mantêm-se em contato por meio da Articulação Nacional de Educação Popular em Saúde surgida em São Paulo no ano de 1991. A articulação toma a forma da Rede de Educação Popular e Saúde em 199912.

Uma nova oportunidade abre-se com a eleição de Lula à presidência da República em 2002. O processo molecular de reorganização dos anos anteriores vai desaguar na mobilização que culmina com a criação da Articulação Nacional de Movimentos e Práticas de Educação Popular e Saúde (Aneps)13, no I Encontro Nacional realizado em Brasília nos dias 5 e 6 de dezembro de 2003. O objetivo é conhecer as experiências de movimentos e práticas locais e refletir sobre suas possíveis contribuições para a política de saúdel4. A iniciativa reúne Mops, Rede de Educação Popular e Saúde, Movimento de Reintegração dos Atingidos pela Hanseníase, Movimento das Mulheres Camponesas, Movimento dos Trabalhadores Sem Terra, Saúde e Alegria (Grupo de Trabalho da Amazônia) e executivas dos movimentos de estudantes da saúde (Stotz, 2004).

\section{Conceitos e ideologia política}

A título de conclusão desta memória, vamos sistematizar os sentidos dos termos Educação Popular, modelo comunitário de organização, trabalho educativo e democratização usados na época aqui analisada. Para tanto, apropriamo-nos das formulações de Maristela Fantin (1988).

Assim, o termo Educação Popular é entendido como educação realizada nos movimentos populares, por meio da participação nas lutas nos mais variados espaços e na dinâmica interna das organizações populares. Tratase de uma educação política que não se dissocia da vida cotidiana, a qual é base para a compreensão dos problemas no bairro e ponto de partida da reflexão sobre as estratificações sociais e de poder que refletem, no nível local, a estrutura social e política mais ampla. As pessoas educam-se na ação desenvolvida, descobrem a solidariedade e a opressão e, pela organização, a esperança de transformar a situação encontrada. A vida cotidiana se amplia, adquirindo sentido político que dela não se dissocia.

Isso ocorre porque a organização do movimento vai além daquela existente nos bairros - sociedades de amigos, escolas de samba, clubes — para incluir uma forma comunitária - a comissão de saúde - que exige a par- 
ticipação de todos na mobilização, no debate, na tomada de decisões e nos encaminhamentos. A dinâmica do trabalho é fundamental para assegurar esta participação igualitária. De acordo com Durhan (apud Fantin, 1988, p. 158), a comissão de saúde é expressão deste 'modelo comunitário'. Segundo a própria definição da Comissão do Movimento:

\footnotetext{
“Nas comissões, o povo é livre e independente, não obedecendo a imposições de nenhuma instituição. Suas leis são a decisão do povo, que participa do trabalho, não aceitando ordens nem chefes. A colaboração e o apoio de todas as instituições (Igrejas; Partidos Políticos; Sociedades de Amigos de Bairro etc.) são aceitos e bem-vindos, desde que respeitados os princípios de trabalho já estabelecidos" (Comissão do Movimento, 1984, p. 8 ).
}

O resultado é uma nova forma de fazer política, na qual os ativistas “passam a intervir na realidade através de atitudes essencialmente educativas. Partindo do real, discutem e analisam os problemas coletivamente, depois retornam ao plano concreto visando um processo de transformação da realidade da qual partiram" (Fantin, 1988, p. 29).

Na experiência da Zona Leste, os moradores, em sua condição de cidadãos, buscam transformar a organização de saúde ao perceberem seus limites e se propõem a assumir um novo relacionamento com os serviços de saúde. Por outro lado, os profissionais de saúde - que até então se vêem na contingência de adaptar as pessoas às exigências do sistema capitalista, reforçando o papel dos doentes como pacientes - descobrem a possibilidade de inverter esse processo, de transformar o conhecimento médico e das ciências da saúde em instrumento para a compreensão das razões das doenças no âmbito do sistema capitalista e para a conquista de crescente autonomia diante deste sistema (Berlinguer, 1983).

Nesse processo, a comissão de saúde situa-se 'ao lado' dos partidos e sindicatos como um novo ator político, um ator capaz de intervir com autonomia na conjuntura. Certamente, esta prática questiona o Estado e a cultura política autoritários que, mesmo sem ter sido percebida pelos atores, ultrapassa em larga medida as exigências da democratização da vida política nacional. Por isso, desperta tantas expectativas quanto à transformação da própria ordem social.

É também o mesmo motivo pelo qual a Educação Popular e Saúde hoje estruturada na Aneps pode reivindicar os sentidos aqui explicitados como seus. 


\section{Notas}

1 Professor do Departamento de Endemias Samuel Pessoa, Escola Nacional de Saúde Pública Sérgio Arouca, Fundação Oswaldo Cruz (Ensp/Fiocruz). Doutor em Ciências da Saúde pela Ensp. <stotz@globo.com>

2 A maioria das obras aqui referidas é de edições esgotadas. Exemplares encontramse dispersos em diversas bibliotecas públicas.

3 No caso da Ensp, a pesquisa toma forma institucionalizada, a partir de 1977, no Programa de Estudos Sócio-Econômicos da Saúde (Peses) e no Programa de Estudos Populacionais e Epidemiológicos (Pepe). Para um estudo sobre a Ensp, ver Nunes (1998).

4 Flávio Goulart registra a articulação informal de uma organização que envolve, no Rio de Janeiro, um grupo de intelectuais, técnicos e professores - Sérgio Arouca, Nelson Rodrigues dos Santos (Nelsão), Hésio Cordeiro, Carlos Gentile de Melo e Carlyle Guerra de Macedo, dentre outros - batizado pelo nome do hotel no qual fazem as reuniões, grupo Novo Mundo (Goulart, 1996).

5 Loyola (1984) refere-se às pesquisas realizadas sob o patrocínio da Organização Mundial da Saúde em países como Índia, Indonésia, Cuba, Guatemala, Irã, Nigéria, Venezuela e China, o que aponta para outras possíveis vertentes inspiradoras da Medicina Comunitária.

6 Entre outubro e novembro de 1980, sob iniciativa do Centro de Estudos de Educação e Sociedade (Cedes) e do Cebes, realiza-se um Curso de Educação e Saúde, no Núcleo Campinas, para dar conta do interesse de pessoas que desenvolvem práticas educativas dirigidas às classes trabalhadoras. Paulo Freire participa do curso com uma apresentação sobre o tema "Educação popular e a saúde". Dentre os textos publicados na revista Cadernos do Cedes organizada por Ana Maria Canesqui, Elizabeth Silvares P. de Camargo e Marilisa Berti de A. Barros em 1984, constam os de Nilson do Rosário Costa, "Estado, educação e saúde: a higiene da vida cotidiana"; de Joaquim Alberto Cardoso de Melo, "Educação sanitária: uma visão crítica"; de Emerson Merhy, "Saúde e movimento popular: o relato de uma experiência"; e de Elza Lobo, "A pesquisa e a metodologia da educação para a saúde".

7 Bohadana menciona outras experiências de trabalho comunitário na saúde: do Bairro Ibiribeira, do Bairro do Coque e dos Coelhos (Recife); de Cangaíba (São Paulo); da Favela do Jardim Londres (Campinas); das Favelas do Chapéu Mangueira, dos Guararapes e do Vidigal (Rio de Janeiro); de Juquiá e Miracatu (Vale da Ribeira); e de Guaimbé (Noroeste Paulista). A Nova Pesquisa, Assessoramento e Avaliação em Educação Pública, nos Cadernos de Educação Popular, os relatos das experiências de Manguinhos (RJ), escrito por Joaquim Alberto Cardoso de Melo; de Medicina Popular em Magé (RJ), escrito por Douglas Carrara; do trabalho dos profissionais de saúde na Zona Leste, escrito por Elza Lobo; dos Projetos Buriticupu e Inhauma (MA), escrito por Antonio Rafael da Silva; e do Bairro dos Coelhos em Recife (Pe), escrito por Paulo Dantas. Ver Lobo (1984).

8 O grupo que chega em Porto Nacional, em 1968, é composto por Eduardo Manzano, Pedro Tauil, Heloisa Lotufo Manzano, Marta Campos, Antônio e Eleonora Azevedo e Brant. Na história de Porto Nacional, aparecem os nomes dos médicos Euvaldo Tomaz de Souza, neto de Francisco Ayres de Souza, e Doris Gramacho. Os estudantes de Porto Nacional e de outras cidades da região norte de Goiás (hoje Tocantins), bastante ativos, organizam-se em torno da Casa do Estudante do Norte Goiano (Cenog). A repressão leva inclusive ao fe- 
chamento da Casa, que é transformada posteriormente em sala de cinema, depois oficina mecânica. Em ruínas, com a abertura política, é recuperada e transformada na sede do campus avançado da Universidade Federal de Goiás.

9 Alguns anos depois, Elza Lobo (1984) sistematiza a reflexão sobre as relações entre profissionais de saúde e população e Paulo Freire (1983) escreve sobre o compromisso do profissional com a sociedade e o papel do trabalhador social no processo de mudança, no primeiro livro publicado após o retorno de quinze anos de exílio (Freire, 1983).

10 De acordo com Sader (apud Fantin, 1988, p. 41), “eram 50 e entre eles os considerados de 'esquerda' predominavam amplamente".

11 De acordo com depoimento de Neilton de Oliveira, dentre muitas experiências avançadas encontravam-se a de Porto Nacional, no então Norte Goiano, e a de Ceres (Goiás), com o parto natural e a humanização da atenção. Na época, a base em Porto Nacional era pública e comunitária e, em Ceres, filantrópica, mas em convênio com o Inamps.

12 Um esboço sobre a trajetória da rede se encontra em Vasconcelos (2001). Para maiores informações, ver também a página <www.redepopsaude.com.br>.

13 A esse respeito, ver acesso 'Aneps', na página <www.redepopsaude.com.br>.

14 Um primeiro passo é a pesquisa encaminhada durante os encontros realizados em 21 estados das cinco macroregiões do Brasil. A pesquisa identifica um total de 802 organizações (movimentos sociais, ONGs, serviços e universidades): a grande parcela $(43,5 \%)$ das organizações com mais de dez anos é um achado que contraria a opinião pessimista de que as organizações com práticas de saúde são recentes, novas e que não duram muito (Albuquerque, Pagliaro e Santos, 2004). Uma referência é o Movimento de Terapia Comunitária que nasce a partir do Projeto 4 Varas, uma iniciativa do médico e antropólogo Adalberto Barreto, da Universidade Federal do Ceará, organizada com moradores da favela do Pirambu, em Fortaleza. O movimento é um exemplo de redes sociais solidárias que mobilizam recursos das pessoas, das famílias e das comunidades, ao incorporar as possibilidades terapêuticas do próprio grupo e valorizar a herança cultural e o saber produzido na experiência de vida de cada participante. 


\section{Referências}

ALBUQUERQUE, Paulette Cavalcanti de. 1994. Planejamento e participação popular em saúde: o caso de Duque de Caxias. Dissertação de Mestrado, Rio de Janeiro: Ensp, Fiocruz.

ALBUQUERQUE, Paulette Cavalcanti de; PAGLIARO, Graciela; SANTOS, Liliana. 2004. Relatório da pesquisa Perfil dos movimentos e práticas em educação popular e saúde no Brasil, 2003. Brasília: Ministério da Saúde/SGTES; Aneps. Disponível em: <www.redepopsaude.com.br>. Acesso em: 2 jan. 2005.

ANDRADE, Regis de C. 1982. Política social e normalização institucional no Brasil. In: CEDEC (Centro de Estudos de Cultura contemporânea) (org.). América Latina: novas estratégias de dominação. $2^{\text {a }}$ ed. Petrópolis: Vozes, p. 87-114.

BERLINGUER, Giovanni. 1983. Medicina e política. $2^{a}$ ed. São Paulo: Hucitec.

BLOCH, Marc. 1993. Introdução à história. $6^{\mathrm{a}}$ ed. Lisboa: Publicações Europa-América.

BOHADANA, Estrella. 1982. Experiências de participação popular em ações de saúde. In: IBASE (Instituto Brasileiro de Análises Sociais e Econômicas) (org.). Saúde e trabalho no Brasil. Petrópolis: Vozes, p. 107-128.

BOLTANSKI, Luc. 1989. As classes sociais e o corpo. $3^{\mathrm{a}}$ ed. Rio de Janeiro: Edições Graal.

CARVAlHO, Antonio Ivo. 1976. Saúde e educação de base: algumas notas. Proposta, n. 3, p. 19-33.

COMISSÃO DO MOVIMENTO. 1984. Histórico do movimento de saúde da Zona Leste de São Paulo. Serviço Social e Sociedade, v. 6, n. 16, p. 5-15.

COSTA, Monica. Comunicação informal ao autor. Recife, 28 dez. 2004.

DONNANGELO, Maria Cecília F.; PEREIRA, Luiz. 1979. Saúde e sociedade. $2^{\text {a }}$ ed. São Paulo: Livraria Duas Cidades.

DURHAN, Eunice. 1984. Movimentos sociais: a construção da cidadania. Novos Estudos, n. 10, p. 24-30.

EQUIPE DAS COMUNIDADES de Base e de Agentes da Diocese de Goiás. 1988.
O meio grito: um estudo sobre as condições, os direitos, o valor e o trabalho popular associados ao problema da saúde em Goiás. In: BRANDÃO, Carlos Rodrigues (org.). Pesquisa participante. $7^{\mathrm{a}}$ ed. São Paulo: Brasiliense, p. 130-198.

ESCOREL, Sarah. 1995. Projeto Montes Claros: palco e bandeira de luta, experiência acumulada do movimento sanitário. In: FLEURY, Sonia (org.). Projeto Montes Claros: utopia revisitada. Rio de Janeiro: Abrasco, p. 129-164.

FANTIN, Maristela. 1988. A prática educativa no movimento de saúde da Zona Leste da Cidade de São Paulo: experiência de dois conselhos populares de saúde. Dissertação de Mestrado, São Paulo: Curso de Pós-Graduação em Filosofia da Educação, PUC-SP. . 2003. Comunicação informal ao autor. Florianópolis, 15 jul. 2003.

FREIRE, Paulo. 1983. Educação e mudança. Rio de Janeiro: Paz e Terra.

GOULART, Flávio A. de A. 1996. Municipalização: veredas - caminhos do Movimento Municipalista de Saúde no Brasil. Rio de Janeiro: Abrasco/Conasems.

LEITE, Simone. Comunicação informal ao autor. Aracaju, 24 dez. 2004.

LOBO, Elza 1984. Desafios na relação profissional/população. Cadernos de Educação Popular, n. 7, p. 17-22.

LOYOLA, Maria Andréa. 1984. Medicina Popular. In: GUIMARÃES, Reinaldo (org.). Saúde e medicina no Brasil: contribuição para um debate. $4^{\text {a }}$ ed. Rio de Janeiro: Graal, p. 225-237.

LUZ, Madel Therezinha. 1986. As instituições médicas no Brasil: instituição e estratégia de hegemonia. $3^{\mathrm{a}}$ ed. Rio de Janeiro: Edições Graal.

. 1996. A arte de curar versus a ciência das doenças: história social da homeopatia no Brasil. São Paulo: Dinamys Editorial.

MOPS. 1994. I Congresso Nacional do MOPS. Jornal Informativo do Movimento Popular de Saúde v. 4, n. 25.

NUNES, Tania C. M. 1998. A especialização em saúde pública e os serviços de saúde 
no Brasil de 1970 a 1989. Tese de Doutorado, Rio de Janeiro: Ensp, Fiocruz.

OLIVEIRA, Jaime A. de A.; TEIXEIRA, Sonia Maria F. 1986. (Im)Previdência Social: 60 anos de história da Previdência no Brasil. Petrópolis-Rio de Janeiro: Vozes/Abrasco.

OLIVEIRA, Neilton A. de. 1983. Prática alternativa de saúde: considerações sobre o trabalho de Porto Nacional e o Movimento Popular de Saúde. Estudos Goianenses, v. 10, n. 1, p. 23-37.

2004. Comunicação informal ao autor. Rio de Janeiro, 14 abr. 2004.

OPAS (Organização Pan-Americana de Saúde). 1979. Informe sobre el Programa Regional de Desarrollo de Recursos Humanos y Investigación Operativa en salud Materno Infantil, en Brasil. Relatório 20/05 a 30/06 de 1979. Washington: Opas.

PELLEGRINI FILHO, Alberto; RAMOS, Célia; RIBEIRO, Joaquim. 1984. A medicina comunitária: a questão urbana e a marginalidade. In: GUIMARÃES, Reinaldo (org.). Saúde e medicina no Brasil: contribuição para um debate. $4^{\mathrm{a}} \mathrm{ed}$. Rio de Janeiro: Graal, p. 207-224.

SADER, Emir. 1988. Quando novos personagens entraram em cena. São Paulo: Paz e Terra.

SOUZA, Eliane de. 2001. Educação popular e saúde: cidadania compartilhada. In: VASCONCELOS, Eymard M. (org.). A saúde nas palavras e nos gestos. São Paulo: Hucitec, p. 30-32.

STOTZ, Eduardo N. 2003. Trabalhadores, direito à saúde e ordem social no Brasil. São Paulo em Perspectiva, v. 17, n. 1, p. 25-33.

STOTZ, Eduardo N. 2004. Encontros de movimentos e práticas de educação popular e Saúde. Interface: Comunicação, Saúde, Educação, v. 18, n. 14, p. 179-182.

STRALEN, Cornelis I.; SOUZA, T. B.; VIEIRA, J. M. F. 1977. A participação comunitária em programas de extensão de cobertura em serviço de saúde. In: XIV Congresso Brasileiro de Higiene e I Congresso Paulista de Saúde Pública, São Paulo. (Mimeo).

TEIXEIRA, Carmem. 1982. Educação em saúde: contribuição ao estudo da formação dos agentes da prática de saúde no Brasil. Dissertação de Mestrado, Salvador: Faculdade de Medicina, Universidade Federal da Bahia.

VASCONCELOS, Eymard M. 2005. Educação popular, um jeito especial de conduzir o processo educativo no setor saúde. Disponível em: <www.redepopsaude.com.br>. Acesso em: 2 jan. 2005.

. 2001. Redefinindo as práticas de saúde a partir da educação popular nos serviços de saúde. In: VASCONCELOS, Eymard M. (org.). A saúde nas palavras e nos gestos. São Paulo: Hucitec, p. 11-19. 